\title{
(2) OPEN ACCESS \\ Combined use of gap-PCR and next-generation sequencing improves thalassaemia carrier screening among premarital adults in China
}

\author{
Jianghong Zhao $\odot,{ }^{1}$ Jia Li, ${ }^{2}$ Qiaohong Lai, ${ }^{1}$ Yanping Yu
}

\begin{abstract}
- Additional material is published online only. To view, please visit the journal online (http://dx.doi.org/10.1136/ jclinpath-2019-206339).

'Department of Obstetrics and Gynecology, Xiaolan Hospital Affiliated to Southern Medical University, Zhongshan, Guangdong province, China ${ }^{2}$ Department of Thyroid and Breast, Shanghai Tenth People's Hospital, Shanghai, China
\end{abstract}

\section{Correspondence to} Dr Jianghong Zhao, Department of Obstetrics and Gynecology, Southern Medical University, Zhongshan, Guangdong province, China; huangbuoying@163.com and Dr Yanping Yu, Department of Obstetrics and Gynecology, Xiaolan Hospital Affiliated to Southern Medical University, Zhongshan, Guangdong province, China; hbjmsr@163. com

Received 15 November 2019 Revised 17 December 2019 Accepted 18 December 2019 Published Online First 24 January 2020

\begin{abstract}
Aims Thalassaemia is one of the most common genetics disorders in the world, especially in southern China. The aim of the present study was to investigate the feasibility of combining the gap-PCR and next-generation sequencing (NGS) for thalassaemia carrier screening in the Chinese population.

Methods Blood samples were obtained from 944 prepregnancy couples; thalassaemia carrier screening was performed by using a routine haematological method and a combination of gap-PCR and NGS method.

Results We found that the $\alpha$ thalassaemia carrier rate was $11 \%$ (207/1888); the $\beta$ thalassaemia carrier rate was $3.7 \%$ (70/1888); the composite $\alpha$ thalassaemia and $\beta$ thalassaemia carrier rate was $0.4 \%$ (8/1888). We also identified seven novel mutations, including $H B A 1$ : c. $412 A>G,-50(G>A), H B B: C^{*}+129 T>A, H B B: C .-$ 64G>C, HBB: C. $-180 \mathrm{G}>\mathrm{C}, H B B:$ C. $^{*}+5 \mathrm{G}>\mathrm{A}$ and HBB: C.$113 A>G$. By comparing the combined gap-PCR and NGS method, the $\mathrm{MCV}+\mathrm{MCH}$ and $\mathrm{HbA} 2$ detection strategy showed a lower sensitivity of $61.05 \%(105 / 172)$ and a higher missed diagnosis ratio of $38.95 \%$ (67/172) for $\alpha$ thalassaemia mutations. The sensitivity was improved with the MCV+MCH and $\mathrm{HbA} 2$ detection screen when compared with $\mathrm{MCV}+\mathrm{MCH}$ detection for $\beta$ thalassaemia (98.51\% vs $85.90 \%)$.

Conclusions Our study suggests the combined gapPCR and NGS method is a cost-effective method for the thalassaemia carrier screening, particularly for the $\alpha$ thalassaemia mutation carriers.
\end{abstract}

\section{INTRODUCTION}

Thalassaemia is one of the most common genetic disorders in the world and is caused by $\alpha$-globin and $\beta$-globin gene mutations. Thalassaemia is distributed mainly in coastal areas of the Mediterranean sea, Africa, the Middle East, India and southeastern Asia. ${ }^{1}$ In China, thalassaemia is mainly distributed in southern China, particularly in Guangxi, Guangdong and Hainan provinces. ${ }^{2-4}$ Most patients with severe thalassaemia may die in utero or during early childhood if untreated. Thus, effective preconception screening is essential for reducing the incidence of thalassaemia in high-prevalence regions of thalassaemia.

Over 1530 mutations ranging from singlenucleotide variations to large rearrangements are associated with thalassaemia or abnormal haemoglobin variants (HbVar database for human HbVar and thalassaemia mutations). Moreover, several variants at various loci have been identified to modify $\beta$ thalassaemia phenotypes. ${ }^{5-7}$ The traditional method uses haematological and biochemical tests and subsequent molecular genetic tests to screen for thalassaemia carriers with phenotypic traits associated with thalassaemia. ${ }^{18}$ Whereas a phenotypic screening approach has a certain weakness in carrier testing, many carriers who have normal or borderline red cell indices and/or $\mathrm{HbA} 2$ levels may be missed. ${ }^{89}$

Next-generation sequencing (NGS) allows for multiplex and high-throughput detection of genetic variants ${ }^{10}$ and is commonly used for diagnosis of genetic disorders. ${ }^{11} 12$ Two recent studies have shown that NGS largely improved thalassaemia carrier screening and had a higher sensitivity and specificity than traditional methods; however, these results might be limited to certain ethnic population or rely only on the NGS technique. ${ }^{13}{ }^{14}$ In the present study, we applied the gap-PCR and NGS techniques to test more than 300 mutations associated with thalassaemia in a cohort of 944 couples pretyped by routine screening methods. Our results suggested that the combined method outperformed traditional methods in the detection of pathogenic or likely pathogenic variants, thus providing an effective platform for application in clinical management of monogenic diseases in a large-scale population.

\section{MATERIALS AND METHODS}

Samples and demographic data

A total of 944 prepregnancy couples between August 2017 and August 2018 were screened for thalassaemia mutations in Xiaolan People's Hospital of Zhongshan. Their age ranged from 23 to 40 years. All individuals provided informed written consent.

\section{Haematological phenotype analysis}

We collected $8 \mathrm{~mL}$ blood samples from each individual for routine blood examinations. An automated haematology analyser was used to detect mean corpuscular volume (MCV) and mean corpuscular haemoglobin $(\mathrm{MCH})$. Participants with an MCV of $<82 \mathrm{fL}$ or an MCH of $<27$ pg underwent Hemoglobin A2 (HbA2) test by the alkaline agarose gel electrophoresis (Helena Spife 3000). An HbA2 value between $2.5 \%$ and $3.5 \%$ was considered normal. When HbA2 was $\leq 2.5 \%, \alpha$ thalassaemia was suspected, whereas when $\mathrm{HbA} 2$ was $\geq 3.5 \%, \beta$ thalassaemia was considered. ${ }^{13}$ 


\section{Reverse dot blot hybridisation (RDB)}

Suspected $\alpha$ thalassaemia and $\beta$ thalassaemia carriers with positive $\mathrm{HbA} 2$ results underwent routine genotyping tests. RDB was performed to detect common $\alpha$ thalassaemia or $\beta$ thalassaemia mutations, including non-deletion-type thalassemia hemoglobin Constant Spring (CS) (HBA2: c.427T >C), Quong Sze (QS) (HBA2: c.377T $>C$ ), Westmead (WS) (HBA2: c.369C $>$ G) and $17 \beta$ thalassaemia mutations, Int (HBB: c.2T>G), CD 41-42 (HBB: c.124_127delTTCT), CD31(HBB: c.94delC), CD14-15 (HBB: c.45466insG), CD17 (HBB: c.52A $>\mathrm{T}), \quad \mathrm{CD} 71-72$ (HBB: c.216_217insA), IVS-I-1 (HBB: c.92+1G>T), CD43 (HBB: c. $130 \overline{\mathrm{G}}>\mathrm{T}$ ), CD27/28 (HBB: c.84_85insC), IVS-II-654 (HBB: c.316-197C>T), -28 (HBB: c. $-78 \mathrm{~A}>\mathrm{G}),-29$ (HBB: c. $-79 \mathrm{~A}>\mathrm{G})$, IVS-1-5 (HBB: c. $92+5 \mathrm{G}>\mathrm{C}), \beta \mathrm{E}(\mathrm{HBB}:$ c. $79 \mathrm{G}>\mathrm{A})$, -32 (HBB: c. $-82 \mathrm{C}>\mathrm{A}),-30$ (HBB: c. $-80 \mathrm{~T}>\mathrm{C})$ and $H B B$ : c. $-50 \mathrm{~A}>\mathrm{C}$. In the RDB assay, the amplified target DNA is first fixed to a nylon membrane to form a filter-fixed DNA dot; the dot is then hybridised to allele-specific oligonucleotide (ASO) probes whose $5^{\prime}$ terminal was conjugated with either P-labelled deoxynucleoside triphosphates, biotin or horseradish peroxidase. All procedures of RDB were conducted following the kit's instructions (YanengBio, Shenzhen, China).

\section{Gap-PCR tests and NGS screening}

As for suspected $\alpha$ thalassaemia and $\beta$ thalassaemia carriers, multiplex gap-PCR was used to detect deletion-type $\alpha$ thalassaemia $\alpha^{3.7},-\alpha^{4.2}$, -- $^{\text {SEA }}$,-- ${ }^{\mathrm{FIL}}$ and -- ${ }^{\mathrm{THAI}}$ and $\beta$ thalassaemia deletions (Chinese Ggamma (Agammadeltabeta) 0, South-East Asia type hereditary persistence of fetal hemoglobin (SEA-HPFH) and Taiwanese). NGS was applied to detect all mutations in $H B A 1, H B A 2$ and $H B B$ genes.

Genomic DNA was extracted from $200 \mu \mathrm{L}$ blood samples using the Kingfisher Flex (Thermo Scientific, Rockford, Illinois, USA) and isolated using the GenMag Nucleic Acid Isolation kit (Magnetic bead method) (GenMagBio, Beijing, China). DNA extracts were arrayed in 96-well plates, and the concentration was quantified by Nanodrop-8000 (Thermo Scientific, Waltham, MA, USA). We restricted our analysis to samples with a DNA concentration $>20 \mu \mathrm{g} / \mathrm{mL}$ and an A260:A280 ratio between 1.8 and 2.0.We designed forward primers and specific reverse primers to amplify $H B A 1, H B A 2$ and $H B B$ genes. PCR indexes were used to distinguish the amplified products. The primers used in this study came from a published article ${ }^{15}$ and patent (patent ID CN108796054A). The HBA1 amplicon size was $919 \mathrm{bp}$; the $H B A 2$ amplicon size was $914 \mathrm{bp}$; and the $H B B$ amplicon size was 599 and $771 \mathrm{bp}$. PCR reactions were performed in 96-well plates, with each sample corresponding to one library. Ninety-six kinds of index sequences were designed, corresponding to each well of the plate. Ninety-six samples were pooled into one tube for further library construction. The detailed experimental protocol was described in a previous study. ${ }^{13}{ }^{15}$ ABI 9700 Thermal Cycler (Life Technologies, Foster City, California, USA) was used in PCR reactions. We adopted NGS library preparation protocol for library construction, including purified genomic DNA (Qiagen DNA Purification kit, Hilden, Germany), DNA quantification (NanoDrop 8000 UV-Vis Spectrophotometer, Thermo Fisher Scientific, Waltham, MA, USA), DNA fragmentation (excluding copy number variation amplicons), blunt-ended fragmentation (Enzymatics kits, Qiagen, Hilden, Germany), 3'-dA overhang, paired-end adapters ligation, DNA fragment separation (copy number variations not included) and size selection using magnetic beads. Sequencing was performed using the paired-end tag (PE100) protocol with an BGISEQ-500 machine (Beijing Genomics Institute, shenzhen, China).

\section{Bioinformatics analyses}

We identified $\alpha$ thalassaemia and $\beta$ thalassaemia deletion genotypes according to the expected amplicon sizes for the deletion junction fragments by agarose gel electrophoresis. For transcripts used to call genetic variants, we required that the sequence depth should be greater than $50 \times$. We developed a bioinformatics pipeline to detect $\mathrm{Hb}$ gene point mutations. First, we filtered low-quality reads and classified remaining reads based on adapter information (index primer). Then, we aligned reads to target region reference using BWA software ${ }^{16}$ and obtained consensus sequence by SAMtools. ${ }^{17}$ Coverage, depth and length were recorded for each consensus using ReSeqTools. ${ }^{18}$ Finally, single-nucleotide variation and indel results were filtered based on sequencing quality and depth. Mutation types were annotated according to the HbVar database of human HbVar and thalassaemia mutations.

\section{Validation of NGS methods}

We applied two different strategies to validate the gap-PCR and NGS approach for detection of thalassaemia carriers. First, we compared four $\alpha$ thalassaemia mutations and eight $\beta$ thalassaemia mutations detected by NGS with the Sanger sequencing results. The mutations analysed included $\alpha$ thalassaemia mutations Hemoglobin $(\mathrm{Hb}) \mathrm{WS}, \mathrm{Hb} \mathrm{CS}, \mathrm{Hb}$ QS and alpha2 codon 30 del GAG and $\beta$ thalassaemia mutations $\mathrm{Hb} \mathrm{E}$, codons $41 / 42$ (-TTCT), IVS-II-654 (C>T), codon $17(\mathrm{~A}>\mathrm{T}),-28(\mathrm{~A}>\mathrm{G})$, $-50(\mathrm{G}>\mathrm{A})$, codons $71 / 72(+\mathrm{A})$ and codon $43(\mathrm{G}>\mathrm{T})$. Second, we compared thalassaemia mutations detected by gap-PCR and NGS with routine genotyping tests (the gap-PCR and RDB method) in 184 individuals with positive $\mathrm{HbA} 2$ results.

\section{RESULTS}

\section{NGS methodological validation}

We initially performed the validation experiment by comparing results generated by NGS and Sanger sequencing independently. Sanger sequencing confirmed $4 \alpha$ thalassaemia mutations and $8 \beta$ thalassaemia mutations detected as positive by NGS results from 12 samples were found to completely match the NGS results (online supplementary figures 1 and 2). Then, among the 184 individuals who underwent routine genotyping and gap-PCR and NGS tests, 152 showed positive $\alpha$ thalassaemia mutations and $\beta$ thalassaemia mutations. Thalassaemia mutations detected by the gap-PCR and NGS were all successfully confirmed by gapPCR and RDB (online supplementary table S1).

\section{Combined gap-PCR and NGS screening reveals thalassaemia mutation carriers}

We applied the combined gap-PCR and NGS method to 944 couples and found that $15.1 \%(285 / 1888)$ of couples were thalassaemia mutation carriers. Of these, the $\alpha$ thalassaemia carrier rate was $11 \%$ (207/1888); the $\beta$ thalassaemia carrier rate was $3.7 \%$ (70/1888); and the composite $\alpha$ thalassaemia and $\beta$ thalassaemia carrier rate was $0.4 \%(8 / 1888)$. Moreover, $2.9 \%$ (27/944) of couples were both estimated as thalassaemia mutation carriers. We identified 20 distinct genotypes of $\alpha$ thalassaemia mutations (online supplementary table S2 and table 1). Among these genotypes, ${ }_{-}{ }^{\mathrm{SEA}} / \alpha \alpha$ was the most common genotype and accounted for $44.4 \%$ of all cases $(92 / 207) .-\alpha^{3.7} / \alpha \alpha$ was the second most common genotype, with an incidence rate of $25.6 \%(53 / 207)$. In addition, we identified 12 carriers with rare 


\begin{tabular}{|c|c|c|c|c|}
\hline Mutation type & HGVS name & Number & Ratio (\%) & Class \\
\hline -- SEA & $\begin{array}{l}\text { NG_000006.1:g.26264_ } \\
\text { 45564del19301 }\end{array}$ & 96 & 42.1 & Common \\
\hline$-\alpha^{3.7}$ & $\begin{array}{l}\text { NG_000006.1:g.34164_ } \\
\text { 37967del3804 }\end{array}$ & 61 & 26.8 & Common \\
\hline Hb Westmead & HBA2: c.369C $>\mathrm{G}$ & 24 & 10.5 & Common \\
\hline$-\alpha^{4.2}$ & NA & 20 & 8.8 & Common \\
\hline $\mathrm{Hb}$ Constant Spring & HBA2: C. $427 \mathrm{~T}>\mathrm{C}$ & 9 & 3.9 & Common \\
\hline Hb Quong Sze & HBA2: c.377T >C & 4 & 1.8 & Common \\
\hline Hb G-Honolulu & HBA2: $c .91 \mathrm{G}>\mathrm{C}$ & 4 & 1.8 & Rare \\
\hline Hb Hekinan II & $H B A 1: c .84 G>T$ & 3 & 1.3 & Rare \\
\hline HBA2: c. $46 G>A$ & $H B A 2:$ c.46G $>A$ & 2 & 0.9 & Rare \\
\hline $\mathrm{Hb}$ Owari & $H B A 1: c .364 \mathrm{G}>\mathrm{A}$ & 2 & 0.9 & Rare \\
\hline HBA2: c.190G >A & HBA2: c.190G >A & 1 & 0.4 & Rare \\
\hline HBA1: c. $412 A>G$ & $H B A 1: c .412 A>G$ & 1 & 0.4 & Novel \\
\hline $\begin{array}{l}\text { Alpha2 codon } 30 \text { del } \\
\text { GAG }\end{array}$ & HBA2: c.91_93delGAG & 1 & 0.4 & Rare \\
\hline Total & & 228 & 100 & \\
\hline
\end{tabular}

genotypes, such as $\mathrm{Hb}$ Hekinan II and Hb Owari. We identified 14 distinct genotypes of $\beta$ thalassaemia mutations (online supplementary table S3 and table 1$)$. The most common genotypes were codons 41/42 (-TTCT) $(34.3 \%, 24 / 70)$ and IVS-II$654(\mathrm{C}>\mathrm{T})(15.7 \%, 11 / 70)$. We also identified $14 \beta$ thalassaemia carriers with rare genotypes which were not detected in previous studies. ${ }^{131920}$ For example, we found that five $\beta$ thalassaemia carriers had a $-50(\mathrm{G}>\mathrm{A})$ mutation. In addition, we identified eight composite $\alpha$ thalassaemia and $\beta$ thalassaemia carriers (online supplementary table S4). Of these, two cases showed a composite $-\alpha^{3.7} / \alpha \alpha$ and codons $41 / 42$ (-TTCT) genotype, and remaining cases showed a unique genotype (online supplementary table S4 and table 2).

\section{Mutation spectrum of $\alpha$-globin and $\beta$-globin genes}

We identified 13 distinct mutations in $\alpha$-globin genes (table 1 ). Most recurrent mutations were consistent with the report of Guangdong province. ${ }^{20}$ The most recurrent two mutations were -- SEA and $-\alpha^{3.7}$, accounting for approximately $68.9 \%$ of all mutations (157/228). Unexpectedly, we noted that the mutation rate of $\mathrm{Hb}$ Westmead was higher than $-\alpha^{4.2}$ in Zhongshan city, which

Table $2 \beta$-Globin gene mutation spectrum

\begin{tabular}{|c|c|c|c|c|}
\hline Mutation type & HGVS name & Number & Ratio (\%) & Class \\
\hline Codons 41/42 (-TTCT) & HBB: c.124_127delTTCT & 29 & 35.8 & Common \\
\hline IVS-II-654 (C>T) & $H B B:$ c.316-197C>T & 14 & 17.3 & Common \\
\hline Codon $17(\mathrm{~A}>\mathrm{T})$ & $H B B:$ c.52A $>T$ & 8 & 9.9 & Common \\
\hline$-28(A>G)$ & $H B B:$ c. $-78 A>G$ & 7 & 8.6 & Common \\
\hline$-50(G>A)$ & $H B B:$ c. $-100 G>A$ & 5 & 6.2 & Novel \\
\hline $\mathrm{HbE}$ & $H B B:$ : $79 \mathrm{G}>\mathrm{A}$ & 4 & 4.9 & Common \\
\hline$H B B: c^{*}+129 T>A$ & $H B B: c^{*}+129 \mathrm{~T}>\mathrm{A}$ & 3 & 3.7 & Novel \\
\hline Codons 71/72 (+A) & $H B B:$ c.216_217insA & 3 & 3.7 & Common \\
\hline Codon $43(\mathrm{G}>\mathrm{T})$ & HBB: c.130G >T & 2 & 2.5 & Common \\
\hline$H B B: c .-64 G>C$ & $H B B:$ c. $-64 G>C$ & 2 & 2.5 & Novel \\
\hline$H B B:$ C. $-180 G>C$ & $H B B:$ : $-180 G>C$ & 1 & 1.2 & Novel \\
\hline$H B B: c^{*}+5 \mathrm{G}>\mathrm{A}$ & $H B B: c^{*}+5 G>A$ & 1 & 1.2 & Novel \\
\hline Hb New York & $H B B:$ : . $341 \mathrm{~T}>\mathrm{A}$ & 1 & 1.2 & Rare \\
\hline HBB: c. $-113 A>G$ & $H B B: c .-113 A>G$ & 1 & 1.2 & Novel \\
\hline Total & & 81 & 100 & \\
\hline
\end{tabular}

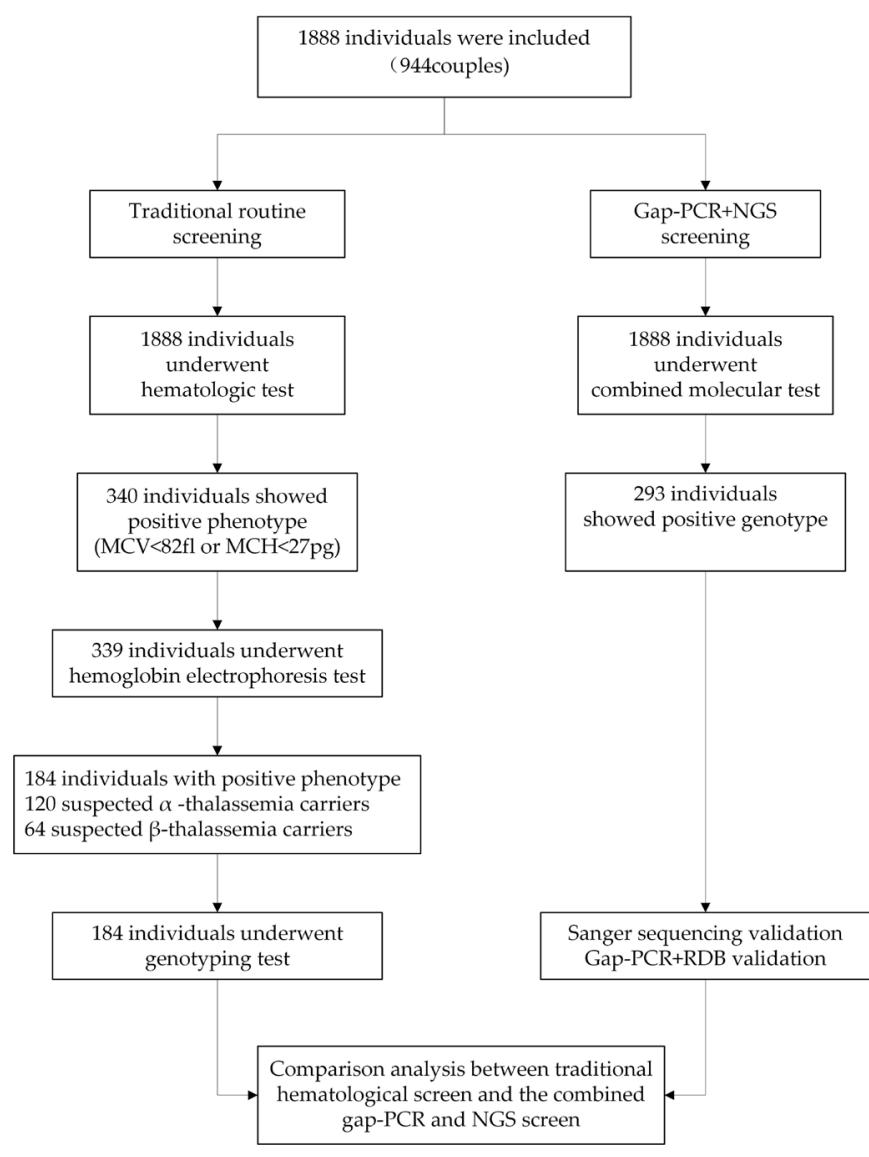

Figure 1 Diagram of work flow and screening results. $\mathrm{MCH}$, mean corpuscular haemoglobin; MCV, mean corpuscular volume; NGS, nextgeneration sequencing; $\mathrm{RDB}$, reverse dot blot hybridisation.

was discordant with that of Guangdong province. ${ }^{20}$ We additionally identified seven rare mutations, such as $\mathrm{Hb}$ Hekinan $\mathrm{II}, \mathrm{Hb}$ G-Honolulu and Hb Owari, accounting for 6.1\% (14/228) of all mutations. Of these, the HBA1: c. $412 \mathrm{~A}>\mathrm{G}$ variant was first identified as a novel $\alpha$-globin gene mutation.

We identified 14 distinct mutations in $\beta$-globin genes (table 2 ). Among these mutations, codons 41/42 (-TTCT) and IVS-II-654 $(\mathrm{C}>\mathrm{T})$ were most prevalent, accounting for $53.1 \%$ (43/81) of all mutations. This was consistent with previous reports. ${ }^{19} \mathrm{We}$ additionally identified seven rare mutations, such as $-50(\mathrm{G}>\mathrm{A})$ and $\mathrm{Hb}$ New York, accounting for $17.3 \%$ (14/81) of all mutations. Of these, $-50(\mathrm{G}>\mathrm{A}), \mathrm{HBB}: \mathrm{c.}{ }^{*}+129 \mathrm{~T}>\mathrm{A}, \mathrm{HBB}: \mathrm{c.}-64 \mathrm{G}>\mathrm{C}$, $H B B$ : c. $-180 \mathrm{G}>\mathrm{C}, \mathrm{HBB}: \mathrm{c} .{ }^{*}+5 \mathrm{G}>\mathrm{A}$ and $H B B$ : c. $-113 \mathrm{~A}>\mathrm{G}$ were identified as $\beta$-globin gene mutations.

\section{Comparison analysis of traditional methods and the combined method}

Based on MCV and MCH (MM) metrics, 18\% (340/1888) of the people showed an abnormal haematological phenotype. Of these, 339 individuals further had a haemoglobin electrophoresis test based on data availability. As a result, 120 and 64 individuals were suspected of being the $\alpha$ thalassaemia and $\beta$ thalassaemia carriers, respectively (figure 1). We estimated the detection rates of $\alpha$ thalassaemia mutations to be $73.49 \%$ by MM $(158 / 215)$ and

$65.12 \%(112 / 172)$ by haemoglobin electrophoresis. The detection rates of $\beta$ thalassaemia mutations by $\mathrm{MM}$ were $85.90 \%$ $(67 / 78)$ and $95.65 \%(66 / 69)$ by haemoglobin electrophoresis (online supplementary table S5). Compared with the combined 


\begin{tabular}{|c|c|c|c|c|c|c|c|c|}
\hline $\mathrm{MM}$ and $\mathrm{HbA2}$ & $\begin{array}{l}\text { Sensitivity } \\
(95 \% \mathrm{Cl})\end{array}$ & $\begin{array}{l}\text { Specificity } \\
(95 \% \mathrm{Cl})\end{array}$ & $\begin{array}{l}\text { PPV } \\
(95 \% \mathrm{Cl})\end{array}$ & $\begin{array}{l}\text { NPV } \\
(95 \% \mathrm{Cl})\end{array}$ & $\begin{array}{l}\text { True } \\
\text { positive }\end{array}$ & $\begin{array}{l}\text { False } \\
\text { positive }\end{array}$ & $\begin{array}{l}\text { True } \\
\text { negative }\end{array}$ & $\begin{array}{l}\text { False } \\
\text { negative }\end{array}$ \\
\hline$\alpha$ thalassaemia & $\begin{array}{l}61.05 \% \\
(53.33 \% \text { to } 68.38 \%)\end{array}$ & $\begin{array}{l}87.65 \% \\
\text { (84.05\% to } 90.70 \%)\end{array}$ & $\begin{array}{l}67.74 \% \\
(61.21 \% \text { to } 73.64 \%)\end{array}$ & $\begin{array}{l}84.12 \% \\
(81.41 \% \text { to } 86.51 \%)\end{array}$ & 105 & 50 & 355 & 67 \\
\hline$\alpha \alpha /--$ SEA & $\begin{array}{l}86.81 \% \\
(78.10 \% \text { to } 93.00 \%)\end{array}$ & $\begin{array}{l}84.36 \% \\
(80.82 \% \text { to } 87.48 \%)\end{array}$ & $\begin{array}{l}50.97 \% \\
\text { ( } 45.44 \% \text { to } 56.47 \% \text { ) }\end{array}$ & $\begin{array}{l}97.16 \% \\
(95.27 \% \text { to } 98.30 \%)\end{array}$ & 79 & 76 & 410 & 12 \\
\hline$\alpha \alpha /-\alpha 3.7$ & $\begin{array}{l}34.21 \% \\
(19.63 \% \text { to } 51.35 \%)\end{array}$ & $\begin{array}{l}73.65 \% \\
(69.72 \% \text { to } 77.33 \%)\end{array}$ & $\begin{array}{l}8.39 \% \\
(5.45 \% \text { to } 12.70 \%)\end{array}$ & $\begin{array}{l}94.08 \% \\
(92.62 \% \text { to } 95.26 \%)\end{array}$ & 13 & 142 & 397 & 25 \\
\hline$\alpha \alpha /-\alpha 4.2$ & $\begin{array}{l}37.50 \% \\
(15.20 \% \text { to } 64.57 \%)\end{array}$ & $\begin{array}{l}73.44 \% \\
(69.58 \% \text { to } 77.05 \%)\end{array}$ & $\begin{array}{l}3.87 \% \\
(2.06 \% \text { to } 7.14 \%)\end{array}$ & $\begin{array}{l}97.63 \% \\
\text { (96.56\% to } 98.37 \%)\end{array}$ & 6 & 149 & 412 & 10 \\
\hline$\beta$ thalassaemia & $\begin{array}{l}98.51 \% \\
(91.96 \% \text { to } 99.96 \%)\end{array}$ & $\begin{array}{l}99.61 \% \\
(98.59 \% \text { to } 99.95 \%)\end{array}$ & $\begin{array}{l}97.06 \% \\
(89.22 \% \text { to } 99.25 \%)\end{array}$ & $\begin{array}{l}99.8 \% \\
(98.64 \% \text { to } 99.97 \%)\end{array}$ & 66 & 2 & 508 & 1 \\
\hline $\begin{array}{l}\text { Codons } 41 / 42 \text { (- } \\
\text { TTCT) }\end{array}$ & $\begin{array}{l}96.55 \% \\
(82.24 \% \text { to } 99.91 \%)\end{array}$ & $\begin{array}{l}92.7 \% \\
(90.19 \% \text { to } 94.73 \%)\end{array}$ & $\begin{array}{l}41.18 \% \\
\text { (34.01\% to } 48.74 \%)\end{array}$ & $\begin{array}{l}99.8 \% \\
(98.67 \% \text { to } 99.97 \%)\end{array}$ & 28 & 40 & 508 & 1 \\
\hline IVS-II-654 (C>T) & $\begin{array}{l}100.00 \% \\
(76.84 \% \text { to } 100.00 \%)\end{array}$ & $\begin{array}{l}90.41 \% \\
(87.67 \% \text { to } 92.71 \%)\end{array}$ & $\begin{array}{l}20.59 \% \\
(16.75 \% \text { to } 25.04 \%)\end{array}$ & $100.00 \%$ & 14 & 54 & 509 & 0 \\
\hline$-28(A>G)$ & $\begin{array}{l}100.00 \% \\
(59.04 \% \text { to } 100.00 \%)\end{array}$ & $\begin{array}{l}89.3 \% \\
(86.47 \% \text { to } 91.71 \%)\end{array}$ & $\begin{array}{l}10.29 \% \\
(8.30 \% \text { to } 12.70 \%)\end{array}$ & $100.00 \%$ & 7 & 61 & 509 & 0 \\
\hline Codon $17(A>T)$ & $\begin{array}{l}100.00 \% \\
(63.06 \% \text { to } 100.00 \%)\end{array}$ & $\begin{array}{l}89.46 \% \\
(86.64 \% \text { to } 91.86 \%)\end{array}$ & $\begin{array}{l}11.76 \% \\
(9.50 \% \text { to } 14.48 \%)\end{array}$ & $100.00 \%$ & 8 & 60 & 509 & 0 \\
\hline
\end{tabular}

$\mathrm{Cl}$, Confidence interval; $\mathrm{MCH}$, mean corpuscular haemoglobin; MCV, mean corpuscular volume; MM, MCV and MCH; NGS, next-generation sequencing; NPV, negative predictive value; PPV, positive predictive value.

method results, the $\mathrm{MCV}+\mathrm{MCH}$ and $\mathrm{HbA} 2$ detection strategy resulted in a lower sensitivity of $61.05 \%(105 / 172)$ and a high missed diagnosis ratio of $38.95 \%$ (67/172) for $\alpha$ thalassaemia. The sensitivity improved with the MM and $\mathrm{HbA} 2$ detection screen when compared with MM detection for $\beta$ thalassaemia (98.51\% vs $85.90 \%$; table 3 and online supplementary tables S5 and S6). Notably, we identified six high-risk couples who have same and abnormal $\alpha$ thalassaemia genotype via NGS. Of these, only three couples were discovered through traditional methods. This demonstrated that the combined approach largely increased the sensitivity and outperformed conventional haematological methods in screening for thalassaemia mutation carriers.

\section{DISCUSSION}

In the present study, we revealed that the $\alpha$ thalassaemia carrier rate was $11 \%$ and the $\beta$ thalassaemia carrier rate was $3.7 \%$, and the composite $\alpha$ thalassaemia and $\beta$ thalassaemia carrier rate was $0.4 \%$ in the Chinese population. The most common $\alpha$ thalassaemia genotype is --SEA/ $\alpha \alpha$, followed by other less common $\alpha$ thalassaemia genotypes, including $-\alpha 3.7 / \alpha \alpha, \mathrm{Hb}$ Westmead and $-\alpha 4.2 / \alpha \alpha$. The prevalent genotypes of $\beta$ thalassaemia are codons 41/42 (-TTCT), IVS-II-654 (C>T) and codon 17 (A>T). Among $\beta$-globin mutants, codons $41 / 42$ show a higher carrier frequency than codon 17. All these findings are in line with previous studies. ${ }^{13}{ }^{14}$ Additionally, we detected some rare $\alpha$-globin and $\beta$-globin gene mutations unpublished by previous studies, ${ }^{56}$ representing $6.1 \%$ and $17.3 \%$ of all mutations, respectively. For example, we identified four cases with an Hb G-Honolulu mutation. This mutation was first identified in a Chinese woman in Singapore and was subsequently observed in southern China. ${ }^{21}$ We also identified seven novel mutations, including HBA1: c. $412 \mathrm{~A}>\mathrm{G},-50(\mathrm{G}>\mathrm{A}), H B B:$ c. $*+129 \mathrm{~T}>\mathrm{A}, \mathrm{HBB}:$ c. $-64 \mathrm{G}>\mathrm{C}$, HBB: c. $-180 \mathrm{G}>\mathrm{C}, H B B:$ c. ${ }^{*}+5 \mathrm{G}>\mathrm{A}$ and $H B B:$ c. $-113 \mathrm{~A}>\mathrm{G}$. Patients with these novel variants showed normal values in haematological indexes. Therefore, it remains to be further elucidated in future studies if these variants are pathogenic

Through comparison analysis, we demonstrated that conventional haematological methods have lower sensitivity, especially for $\alpha$ thalassaemia detection, and a large fraction of thalassaemia variants with clinical significance like --SEA, $-\alpha 3.7$ and $-\alpha 4.2$ were not detected because the patients usually have normal values in $\mathrm{MCV}, \mathrm{MCH}$ and $\mathrm{HbA} 2$ indexes. The sensitivity of $\mathrm{MM}$ combined with HbA2 improved when compared with $\mathrm{MM}$ in the detection for $\beta$ thalassaemia mutations $(92.75 \%$ vs $85.90 \%)$. These findings are consistent with a previous study. ${ }^{13}$ Although there are some similar studies on the application of NGS to the detection of thalassaemia mutations in China, He et al's ${ }^{13}$ and Yao et $a l^{\prime} \mathrm{s}^{3}$ studies focused on the spectrum of thalassaemia mutations and evaluated the performance of NGS in screening for thalassaemia mutations in Chinese ethnic minorities. Zhang et al's study ${ }^{22}$ lacked quantitative measures of the performance of NGS in the general Chinese population. For the first time, our study provided an in-depth comparison between traditional haematological methods and combined gap-PCR and NGS, which further demonstrated that the combined method outperformed the traditional haematological method in screening for thalassaemia mutations, particularly for $\alpha$ thalassaemia mutation carriers, in the general Chinese population.

The gap-PCR and NGS combined method has various advantages over the traditional haematological screening method. The major factors affecting the application of NGS are the high cost of sequencer, reagent and additional bioinformatics technicians. Whereas the NGS strategy shows a substantial advantage in time and cost in a large-scale population screening, in this study, the NGS had a throughput of 3000 samples per run, and the combined gap-PCR and NGS costs approximately US $\$ 25$ for each sample, which is similar to that of the traditional method combined with gap-PCR or PCR-RBD (\$25). Therefore, NGS is cost-efficient to screen for thalassaemia mutations in a largescale population. Third, the combined method detects a wider spectrum of mutations, including common, rare, annotated and novel variants; therefore, it remarkably increases the detection rates of carrier status and therefore improves the detection rate of at-risk couples at a relatively low cost. Given the strengths of the combined gap-PCR and NGS method, we believe it can completely replace the haemoglobin electrophoresis screening 
step. In the prepregnancy or pregnancy screening, if the routine blood tests suggest small cell low-pigment anaemia, the gapPCR and NGS combined detection should be carried out for the patients. Based on the results of gap-PCR and NGS combined detection, prenatal counselling can be more accurate so as to avoid abortion of fetuses with severe thalassaemia at late pregnancy or before pregnancy.

Though our study demonstrated the combined gap-PCR and NGS method outperformed routine haematological method in the detection of the thalassaemia mutations, it might have certain limitations. First of all, the study population was relatively small and confined to the Zhongshan city from Guangdong province. The results might have regional bias, therefore, further studies are required to validate the findings in a larger sample population from multiple regions of South China. Secondly, the pathogenicity of novel thalassaemia mutations remained unknown; their phenotypic effect should be validated in future studies. In summary, we systematically characterised thalassaemia carrier rate and mutation spectrum of $\alpha$-globin and $\beta$-globin genes using gap-PCR and NGS among Chinese people. Our study has great value for preventing major thalassaemia in China while laying the groundwork for clinical application of the gapPCR and NGS combined method to thalassaemia carrier screening.

Take home messages

- The first comprehensive survey of thalassaemia gene mutations was performed in the Zhongshan region.

- The $\alpha$ thalassaemia carrier rate was $11 \%(207 / 1888) ;$ the $\beta$ thalassaemia carrier rate was $3.7 \%$ (70/1888); and the composite $\alpha$ thalassaemia and $\beta$ thalassaemia carrier rate was $0.4 \%$ (8/1888). Seven novel mutations were identified, including HBA1: c.412A $>\mathrm{G},-50(\mathrm{G}>\mathrm{A}), H B B: \mathrm{c}^{*}{ }^{*}+129 \mathrm{~T}>\mathrm{A}$, $H B B:$ c. $-64 \mathrm{G}>\mathrm{C}, H B B: \mathrm{C} .-180 \mathrm{G}>\mathrm{C}, H B B: \mathrm{C} .^{*}+5 \mathrm{G}>\mathrm{A}$ and $H B B$ : C. $-113 \mathrm{~A}>\mathrm{G}$.

- The combined gap-PCR and NGS method outperformed the $\mathrm{MCV}+\mathrm{MCH}$ and $\mathrm{HbA2}$ method and MCV+MCH method in the detection of $\alpha$ thalassaemia and $\beta$ thalassaemia mutations.

\section{Handling editor Mary Frances McMullin.}

Acknowledgements The authors thank all the staff of their department for their kind help and Dr Shiping Chenfor technical support.

Contributors YY designed the study and wrote the article; IZ and QL performed routine thalassemia analysis; QL performed the specific gap-PCR amplification and the DNA sequencing; JL wrote the manuscript and provided technical support. All authors approved the final manuscript.

Funding This research was financially supported by Science and Technology Planning Project of Zhongshan (grant/award number 2017B1007).

Competing interests None declared.

Patient consent for publication Not required.

Ethics approval This study was approved by the medical ethics committee of Xiaolan People's Hospital of Zhongshan (XLLL-2017-KY-001).

Provenance and peer review Not commissioned; externally peer reviewed.
Data availability statement Data are available upon reasonable request. All data relevant to the study are included in the article or uploaded as supplementary information.

Open access This is an open access article distributed in accordance with the Creative Commons Attribution Non Commercial (CC BY-NC 4.0) license, which permits others to distribute, remix, adapt, build upon this work non-commercially, and license their derivative works on different terms, provided the original work is properly cited, appropriate credit is given, any changes made indicated, and the use is non-commercial. See: http://creativecommons.org/licenses/by-nc/4.0/.

\section{ORCID iD}

Jianghong Zhao http://orcid.org/0000-0002-4074-9476

\section{REFERENCES}

1 Cao A, Kan YW. The prevention of thalassemia. Cold Spring Harb Perspect Med 2013:3:11775.

2 Xiong F, Sun M, Zhang X, et al. Molecular epidemiological survey of haemoglobinopathies in the Guangxi Zhuang autonomous region of southern China. Clin Genet 2010;78:139-48.

3 Yao $H$, Chen $X$, Lin L, et al. The spectrum of $\alpha$ - and $\beta$-thalassemia mutations of the Li people in Hainan Province of China. Blood Cells, Mol Dis 2014;53:16-20.

$4 \mathrm{XM} \mathrm{X}$, Zhou YQ, Luo GX, et al. The prevalence and spectrum of $\alpha$ and $\beta$ thalassaemia in Guangdong Province: implications for the future health burden and population screening. J Clin Pathol 2004;57:517-22.

5 Giardine B, Borg J, Higgs DR, et al. Systematic documentation and analysis of human genetic variation in hemoglobinopathies using the microattribution approach. Nat Genet 2011:43:295-301.

6 Sankaran VG, Weiss MJ. Anemia: progress in molecular mechanisms and therapies. Nat Med 2015;21:221-30.

7 Thein SL. Genetic association studies in $\beta$-Hemoglobinopathies. Hematology 2013;2013:354-61.

8 Traeger-Synodinos J, Harteveld CL, Old JM, et al. EMQN best practice guidelines for molecular and haematology methods for carrier identification and prenatal diagnosis of the haemoglobinopathies. Eur J Hum Genet 2015;23:426-37.

9 Piel FB, Weatherall DJ. The $\alpha$-thalassemias. N Engl J Med 2014;371:1908-16.

10 Korf BR, Rehm HL. New approaches to molecular DiagnosisNew approaches to molecular diagnosis. JAMA 2013;309:1511-21.

11 Stark Z, Tan TY, Chong B, et al. A prospective evaluation of whole-exome sequencing as a first-tier molecular test in infants with suspected monogenic disorders. Genet Med 2016;18:1090-6.

12 Yang Y, Muzny DM, Reid JG, et al. Clinical whole-exome sequencing for the diagnosis of Mendelian disorders. N Engl J Med 2013;369:1502-11.

13 He J, Song W, Yang J, et al. Next-Generation sequencing improves thalassemia carrier screening among premarital adults in a high prevalence population: the DAI nationality, China. Genet Med 2017;19:1022-31.

14 Shang $X$, Peng Z, Ye Y, et al. Rapid targeted next-generation sequencing platform for molecular screening and clinical genotyping in subjects with hemoglobinopathies. EBioMedicine 2017;23:150-9.

15 Tan AS, Quah TC, Low PS, et al. A rapid and reliable 7-deletion multiplex polymerase chain reaction assay for alpha-thalassemia. Blood 2001;98:250-1.

16 Li H, Durbin R. Fast and accurate short read alignment with Burrows-Wheeler transform. Bioinformatics 2009:25:1754-60.

17 Li H, Handsaker B, Wysoker A, et al. The sequence Alignment/Map format and SAMtools. Bioinformatics 2009;25:2078-9.

18 He W, Zhao S, Liu X, et al. ReSeqTools: an integrated toolkit for large-scale next-generation sequencing based resequencing analysis. Genet Mol Res 2013;12:6275-83.

19 Zhang C-M, Wang Y, Gao L-S, et al. Molecular epidemiology investigation of $\beta$-thalassemia in Zhongshan City, Guangdong Province, people's Republic of China. Hemoglobin 2010;34:55-60.

20 Yin A, Li B, Luo M, et al. The prevalence and molecular spectrum of $\alpha$ - and $\beta$-globin gene mutations in 14,332 families of Guangdong Province, China. PLoS One 2014:9:e89855.

21 Wang PP, Lin M, JR W, et al. Wang PP1, Lin M, Wu JR, Wang XY yl. three cases of the hemoglobin G-Chinese variant detected in patients of southern Chinese origin. $\mathrm{Mol}$ Med Rep 2010;3:459-61.

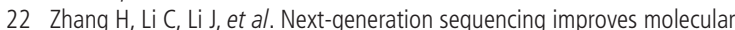
epidemiological characterization of thalassemia in Chenzhou region, P.R. China. J Clin Lab Anal 2019;33:1-9. 